\title{
Environmental Sustainability Through Exploitation of Alternative Energy Sources (AES) in Akwa Ibom State, Nigeria
}

\author{
Udoh Felix Evans ${ }^{1}$, Gideon Umoh ${ }^{2}$, Nsikan Okon James ${ }^{2}$, Owoidighe Hilary ${ }^{3}$ \\ ${ }^{1}$ Department of Strategy, Research \& Development, Directorate of Strategy, Research \& Development, Maritime Academy of Nigeria, Oron, \\ Nigeria \\ ${ }^{2}$ Department of Electrical/Electronics, School of Marine Engineering, Maritime Academy of Nigeria, Oron, Nigeria \\ ${ }^{3}$ Department of Maritime Transport, Maritime Academy of Nigeria, Oron, Nigeria
}

Email address:

udohevans@gmail.com (U. F. Evans)

\section{To cite this article:}

Udoh Felix Evans, Gideon Umoh, Nsikan Okon James, Owoidighe Hilary. Environmental Sustainability Through Exploitation of Alternative Energy Sources (AES) in Akwa Ibom State, Nigeria. American Journal of Environmental Science and Engineering.

Vol. 3, No. 1, 2019, pp. 17-21. doi: 10.11648/j.ajese.20190301.13

Received: December 3, 2018; Accepted: January 20, 2019; Published: February 28, 2019

\begin{abstract}
In order to drive sustainable human development for the optimization of productivity and economic growth as well as clean environment, the study on alternative energy sources (AES) suitable for exploitation was carried out in Akwa Ibom State, Nigeria. The study area was the three Senatorial Districts of Akwa Ibom State. Ten houses from each of the Senatorial Districts were surveyed and the statistical properties of their septic tanks and numbers of occupants were collected. The septic tank properties were size (measured in metres) and the dislodged time (measured in years). Data show that an average septic tank size is $4 \times 3 \times 4$ for length, width and depth respectively, with an estimated dislodged time of 10years for five adult occupants. By allowing for baffle wall, the volume of the septic tank was determined, the mass of biogas generated was computed to be $30.42 \mathrm{~kg}$. The bioenergy that could be generated from biogas of mass $30.43 \mathrm{~kg}$ was estimated at $144.86 \mathrm{kwh}$ per dislodged by using empirical relationships. This energy generated in sewers by biomass when converted to other forms of energy can be enormous for local use. Within the alternative energy sources, the study recommends the use of biomass since most houses in Uyo have private septic tanks as sewers for soil waste. This makes it readily available in the environment. With appropriate policies in place and adequate encouragement in the use of biomass energy, the present gasoline power generators used in various homes could be replaced to ensure environmental sustainability in Akwa Ibom State.
\end{abstract}

Keywords: Energy, Biomass, Bioenergy, Fossil, Sustainability, Environment

\section{Introduction}

Energy is one of the diurnal requirements needed in driving human development for the optimization of productivity and economic growth. Energy is essential for heating, lighting, cooking, space comfort, mobility and communication as well as health service delivery. The principle of Physics shows that no work is done without energy, and energy exists in many different forms. Some forms of energy are solar energy, which carries energy from the sun to earth; chemical energy, which is used in batteries for the production of electricity. Other forms of energy are heat energy and electrical energy. For interacting systems, energy can be converted from one form to another, but it cannot be destroyed. It is most unfortunate that, the global energy demand increases by the day, giving ways for exploration and exploitation of more sources of energy [1, 2].

The world's increasing demand for energy stems from population explosion, which has led to the continual use of carbon-based energy sources (fossil fuel) other than the traditional fire wood, since the overuse of traditional fire wood as energy source led to extensive global deforestation. At present, the most popular energy source worldwide is derived from carbon-based remains, which slowly build up into combustible hydrocarbon substances called fossil fuel; such includes crude-oil, natural gas and coal. However, the offshoots of fossil fuel have seen to constitute major sources of atmospheric pollution with it attendant effects on the environment [3]. The increasing use of fossil fuel has increased geometrically the risk on the environment at global scale. Therefore, as the over dependency on fossil-based 
energy sources become more problematic by generating several environmental and economic challenges such as depletion of fossil fuel reserves, continual fuel price fluctuations, government-pressure groups conflicts, greenhouse gas emissions and other environmental concerns, there arose a need for alternative energy sources [1, 4]. At a certain time, nuclear energy was seen as the answer to the global energy problem as it produces huge amounts of energy from a small amount of uranium. But like fossil fuels, uranium is also a natural and finite resource, with attendant potentially irreversible threat to human health and the environment [5]. Hence, nuclear energy source would not serve the human society in any way better than the fossilenergy source. Therefore, an alternative energy source generally should be any group of fuel source that does not burn fossil fuels or use up any type of natural resources which will result in damage or harm to the environment. Alternative energy sources are expected to fill the gap between the non-realistic free energy sources and the more traditional fossil fuel energies of oil, gas and coal. Generally, alternative energy sources are types of energy fuels that can be used instead of burning fossil fuels or the splitting of atoms. But alternative energy sources are not all the same as their applications, accessibility, availability; economics and energy output are all different. The downside however, is that alternative energy sources are not always available when we need them. For instance, sometimes the wind does not blow or the sun does not shine because of the Earth's rotation, which produce day and night. However, the knowledge of the interactions between sustainable development and alternative energy sources is still limited especially in developing countries. It is in the light of the potential threat to humans and the environment by the over dependency on fossil fuel that this paper is set out to investigate suitable and sustainable alternative energy sources in the Nigerian Niger Delta.

\section{Energy Sources in the Nigerian Niger Delta}

At present, the major source of energy in Nigeria is the fossil fuel, and the economy of the country depends heavily on it. Fossil fuels during combustion do not only produce usable energy but also releases large amounts of carbon dioxide as by-product [6]. In recent times, the by-product of fossil fuel has contributed to increasing greenhouse gases and by implication, global warming. Other greenhouse gases and their sources include methane, which comes from such sources as swamps and gas emitted by livestock, and chlorofluorocarbons (CFCs), which were used in refrigerants and aerosol propellants until they were banned because of their deteriorating effect on Earth's ozone layer [7].

The increasing concentrations of Carbon dioxide $\left(\mathrm{CO}_{2}\right)$, Nitrogen dioxide $\left(\mathrm{NO}_{2}\right)$, Sulfur dioxide $\left(\mathrm{SO}_{2}\right)$, Ozone $\left(\mathrm{O}_{3}\right)$, and Ammonia $\left(\mathrm{NH}_{3}\right)$ in the atmosphere is as a result of increase in energy demand worldwide for industrialization, transportation, recreation and maintenance of infrastructure [8]. This has set our ecosystem under attack. Therefore, the prime concern of international communities has been how to mitigate environmental hazards due to the popular use of fossil fuel and one of the ways is by carefully considering alternative sources of energy in terms of availability, reliability and sustainability. In clear terms, alternative energy should not only have the potential of meeting energy needs, but should provide excellent solutions to some environmental problems, ensure a sustainable future and bequeath future generations to meet their energy needs. Most sources of alternative energy depend obviously on natural sources of energy such as the sun, the wind and water [1].

In order to reduce the amount of greenhouse gas in the atmosphere, most countries are at present sequestrating Carbon dioxide from the environment. In addition, the ongoing global campaign against gas flaring to reduce the impact of greenhouse gases on the environment has further made research on alternative sources of energy popular. The opportunities associated with alternative energy sources include: energy security, energy access, social and economic development and climate change mitigation and reduction of environmental and health impacts. All these sources hold the potential for producing usable alternative sources of energy. In developed countries, energy sources such as wind, solar, hydropower and biomass are now being explored as alternative energy sources in order to attain sustainable environmental system. Therefore, diversifying fuel supply from the fossil had not only led to the discovery of environmental-friendly energy sources but contributes to the optimization of the economy.

\section{Greenhouse Gases and Environmental Challenges}

From the beginning of creation, the climate has been changing due to changes in climatic variables, but what is alarming in recent years is the rate at which this change is taking place. One of the fastest increasing substances witnessed on Earth, is the presence of greenhouse gases in the atmosphere, and has trigged global warming. Carbon dioxide in the atmosphere has increased tremendously over the past 36 years (1979-2014) and is now a potential environmental threat [2]. These increases constitute global warming, and its increasing effects have shed light on many global environmental issues such as atmospheric pollutants. Carbon dioxide is one of the greenhouse gases (atmospheric pollutants), and it is the main pollutant that is warming the Earth [9]. Even when humans emit Carbon dioxide as they breathe, Carbon dioxide associated with cars, planes, power plants, and other human activities that involve the burning of fossil fuels such as gasoline and natural gas is widely considered to be a pollutant.

Another pollutant associated with climate change is sulfur dioxide, a component of smog. Sulfur dioxide and closely related chemicals are known primarily as a cause of acid rain $[3,10]$. But they also reflect light when released in the atmosphere, which keeps sunlight out and causes Earth to cool. Volcanic eruptions have been seen to spew massive amounts of sulfur dioxide into the atmosphere, sometimes causing cooling that lasts for years. In fact, volcanoes used 
to be the main source of atmospheric sulfur dioxide.

Industrialized countries have worked to reduce levels of sulfur dioxide, smog, and smoke in order to improve on the quality of people's health [11]. But a result, not predicted until recently, is that, lower sulfur dioxide levels may increase global warming. Just as sulfur dioxide from volcanoes can cool the planet by blocking sunlight, cutting the amount of the compound in the atmosphere lets more sunlight through, warming the Earth. This effect is exaggerated when elevated levels of other greenhouse gases in the atmosphere is been trapped. A significant climate change has become one of the greatest challenges of the twenty-first century [12]. Its grave impacts may still be avoided if efforts are made to transform the current energy systems (fossil fuel). Alternative energy sources hold the key potential to displace greenhouse gas emissions from fossil fuel-based power generating and thereby mitigating climate change [13].

\section{Alternative Energy Sources and Environmental Sustainability}

Research into alternate energy sources dated back to the late 90s when the world started receiving shock from oil producers in terms of price hiking $[14,15]$. Alternative energy sources replenish themselves naturally without being depleted. Securing energy supply and curbing energy contribution to climate change are the two-over-riding challenges of the energy sector on the road to a sustainable future [16]. Alternative energy sources are energy sources from natural and persistent flow of energy existing in our immediate environment. For instance, the sun covers the earth daily with sunlight, which can be turned into heat or electricity. The movement of the wind and rivers produces kinetic energy (the energy of matter in motion), while ocean tides raise and lower the sea level with an unstoppable force which also produces kinetic energy. All these sources hold the potential for producing usable alternative sources of energy.

Typically, alternative energy includes: hydropower, bioenergy, direct solar energy, geothermal energy, wind and ocean energy (tide and wave). Each of the alternative energy sources is inclined towards a particular criterion [17]. For instance, solar is inclined towards economy, biomass towards social, hydropower towards technical, and wind towards environmental aspect. Alternative energy sources have the potential of environmental sustainability. Despite this potential, there are challenges that hinder the development of alternative energy sources in Nigeria and other developing countries of the World. These challenges include market failures, economic standard, lack of proper information, access to raw materials for future deployment, environmental impact and our daily carbon footprint [18].

Recently, sustainable development (SD) has become the centre of national policies, strategies and development plans of many countries. SD places greater value and demands on the scientific community than did the Millennium Development. In addressing climate change, alternative energy, food security, health and water provision requires a coordinated global monitoring and modelling of many factors which are socially, economically and environmentally oriented. Governments, intergovernmental agencies, interested parties and individuals in the world today look forward to achieving a sustainable future due to the opportunities created in recent decades to replace petroleumderived materials from fossil fuel-based energy sources with alternatives in renewable energy sources [19]. Alternative sources of energy are known to produce clean energy and optimal use of these resources; they decrease environmental impact, produce minimum secondary waste and are sustainable based on the current and future socio-economic needs [17].

In spite of the outstanding advantages of alternative energy sources, certain shortcoming exists such as: the discontinuities of generation due to seasonal variations as most alternative energy resources are climate-dependent, that is why its exploitation requires complex design, planning and control optimization methods. When looking at sustainable energy sources, we commonly identify four: solar, wind, hydro and biomass. Each of them is renewable, but that does not necessarily make them sustainable. This research considered three indices in defining energy sustainability, which are environmental sustainability, social sustainability and economic sustainability.

\subsection{Hydropower Fuel}

Hydropower is an essential energy source derived from water moving from higher to lower elevation levels, and channeled primarily to turn turbines which generate electricity. Therefore, the primary energy is provided by gravity and the height the water which falls on the turbine. The potential energy of the stored water is the mass of the water, the gravity factor $\left(\mathrm{g}=9.81 \mathrm{~ms}^{-2}\right)$ and the head defined as the difference between the dam level and the tail water level. The reservoir level to some extent changes downwards when water is released and accordingly influences electricity production [20]. Turbines are constructed for an optional flow of water. Hydropower operates without the discharge of particulate pollution, it can be renewed easily, and it is capable of storing energy for many hours. The operation of hydropower reservoirs often reflects their multiple uses, which are flood and drought control besides generation of electricity. However, the resource potential of hydropower could be altered due to climate change. In addition, the exploitation of the sites for hydropower such as, reservoirs that are often artificially created leading to flooding of former natural dry environment. In hydropower operation, water is drained from lakes and watercourses and transported through channels over large distances (sometimes through rough terrain) and to pipelines and finally to the turbines that are often visible. This makes the entire process difficult and capital intensive. Also, hydropower system affects water body ecology, largely by inducing changes into its hydrologic characteristics and by disturbing the ecological continuity of sediment transport and fish migration when dams, dikes and weirs are built. Therefore, cannot be relied upon since the three indices that measure energy sustainability are not met. 


\subsection{Estimation of Biomass Energy from Human Waste}

Momentarily, coal-based fuel became the most preferred fuel for locomotives because it has higher energy carrying capacity than corresponding quantities of biomass-based fuels (firewood and charcoal). It is noteworthy that coal was comparatively cheaper and a much cleaner fuel as well in the past centuries [13]. Bioenergy is the energy derived from the biomass also called organic matter. It can be made from agricultural crops and plant materials such as wood, sawdust, peat, poultry litter, energy croups (such as willow and neem leaves), rice husks, sugar cane bagasse, cow dung and biodegradable municipal waste and human soil waste, as well as straw grown specifically to be burnt as a fuel. Bioenergy is sustainable because its source (biomass) is replenished as new crops and forests are grown to replace those that have been harvested. In addition, human and animal wastes cannot be exhausted so long as the species exist, and it is cost effective, environmental-friendly, insured continual fuel supply and socially sustainable. This energy source addresses the three indices for measuring energy sustainability.

A survey of houses in the three Senatorial Districts of Akwa Ibom State shows that based on frequency, a septic tank compartment in a compound of 5 occupants measures 4 x $3 \times 4 \mathrm{~m}$, for length, width and depth, and is dislodged after 10years (Table 1). If we subtract $2 \times 0.225 \mathrm{~m}$ to allow for baffle wall, the volume of watered biomass can be estimated using the conventional formula for volume of a rectangle, so that we have:

$$
4 \times 3 \times 3.55 \mathrm{~m}=42.6 \mathrm{~m}^{3}
$$

Table 1. Septic tank sizes and their usage in selected houses in Akwa Ibom State.

\begin{tabular}{|c|c|c|c|c|c|c|c|}
\hline $\mathbf{S} / \mathbf{N}$ & Size (m) & No. of Adult occupants & Dislodged time (Years) & $\mathbf{S} / \mathbf{N}$ & Size (m) & No. of Adult occupants & Dislodged time (Years) \\
\hline 1 & $4 \times 3 \times 4$ & 5 & 10 & 16 & $4 \times 3 \times 4$ & 5 & 11 \\
\hline 2 & $4 \times 3 \times 4$ & 5 & 10 & 17 & $4 \times 3 \times 4$ & 5 & 10 \\
\hline 3 & $4 \times 3 \times 4$ & 5 & 9.5 & 18 & $4 \times 3 \times 4$ & 5 & 10 \\
\hline 4 & $4 \times 3 \times 4$ & 5 & 11 & 19 & $4 \times 3 \times 4$ & 5 & 10 \\
\hline 5 & $4 \times 3 \times 4$ & 5 & 10 & 21 & $4 \times 3 \times 4$ & 5 & 10 \\
\hline 6 & $4 \times 3 \times 4$ & 5 & 10.5 & 22 & $4 \times 3 \times 4$ & 5 & 10 \\
\hline 7 & $4 \times 3 \times 4$ & 5 & 9.5 & 23 & $4 \times 3 \times 4$ & 5 & 10 \\
\hline 9 & $4 \times 3 \times 4$ & 5 & 10 & 25 & $4 \times 3 \times 4$ & 5 & 10 \\
\hline 10 & $4 \times 3 \times 4$ & 5 & 10 & 26 & $4 \times 3 \times 4$ & 5 & 10 \\
\hline 11 & $4 \times 3 \times 4$ & 5 & 9.5 & 27 & $4 \times 4 \times 4$ & 5 & 10 \\
\hline 12 & $4 \times 3 \times 4$ & 5 & 10 & 28 & $4 \times 3 \times 4$ & 5 & 12 \\
\hline 13 & $4 \times 3 \times 4$ & 5 & 10 & 29 & $4 \times 4 \times 4$ & 5 & 12 \\
\hline 14 & $4 \times 3 \times 4$ & 5 & 10 & 30 & $4 \times 3 \times 4$ & 5 & 12.5 \\
\hline 15 & $4 \times 3 \times 4$ & 5 & 10 & & & & \\
\hline
\end{tabular}

N/B: Size is given in the order of length, width and depth.

By analyzing anaerobic digestion of biomass wastes from sewer to produce methane gas which is the energy source from biomass, we consider a simple gas plant digestion of biomass with fuel consumption of $3415 / 0.34$, where 0.34 is the plant factor. By convention, $1 \mathrm{kwh}=3415 \mathrm{Btu}$ and the net heating value of methane $=21433 \mathrm{Btu} /$ pound .

Therefore, methane consumption capacity is given as

$$
E_{r}=\frac{10000}{H_{v}}=0.47 \text { pounds } / \mathrm{kwh}=0.21 \mathrm{Kg} / \mathrm{kwh}
$$

where $E_{r}$ is mass per energy and $H_{v}$ net heating value. $1 / E_{r}$ is the multiplication factor for converting biogas mass to useful energy in kwh.

Recall, 1000 litres $=1 \mathrm{~m}^{3}$ and 22.4 litres $=1 \mathrm{~mol}$ of the substance

Molar mass of methane $=16 \mathrm{~g} / \mathrm{mol}$

$$
\text { Hence, density of methane }=\frac{16 \mathrm{~g} / \mathrm{mol}}{22.4 \mathrm{~mol}} \times 1000 / \mathrm{m}^{3}
$$

Thus density $=714 \mathrm{~g} / \mathrm{m}^{3}=0.714 \mathrm{Kg} / \mathrm{m}^{3}$

The mass of methane $\left(\mathrm{m}_{\mathrm{m}}\right)$ that can be extracted from biomass of volume $42.6 \mathrm{~m}^{3}$ is calculated by

$$
\mathrm{m}_{\mathrm{m}}=0.714 \times 42.6=30.42 \mathrm{Kg}
$$

The energy $\left(E_{m}\right)$ generated from this mass $(30.42 \mathrm{Kg})$ of methane can be calculated by

$$
E_{m}=\frac{m_{m}}{E_{r}}
$$

So that methane (biogas) produced by the biomass will generate $144.86 \mathrm{kwh}$ of energy. This implies that a septic tank used by 5 occupants is capable of generating $144.86 \mathrm{kwh}$ of energy per dislodgement. Research has showed that a given mass of human waste has the capacity of generating at least $70 \%$ of biogas (methane) [21]. Therefore, a given volume of human waste should produce $70 \%$ volume of biogas and $70 \%$ useful energy. In line with this, $42.6 \mathrm{~m}^{3}$ of human waste will produce $101.42 \mathrm{kwh}$ of energy.

By considering the density of human waste to be the same as that of water $\left(1000 \mathrm{Kg} / \mathrm{m}^{-3}\right)$, the volume of the septic tank and years before dislodged, the estimated mass of biomass per year will be $4260 \mathrm{~kg} /$ year. Taking into account $70 \%$ efficiency, the mass biogas can be estimated at $2982 \mathrm{~kg} /$ year. This further means that 5 occupants generate $8.17 \mathrm{~kg}$ /day mass of biomass. Therefore, a person is supposed to generate $1.63 \mathrm{~kg}$ biomass per day. This is capable of producing mass of methane gas of $1.63 \mathrm{x}$ $0.714=1.17 \mathrm{~kg}$. By applying the multiplication factor of $1 / 0.21$, this biogas mass could produce $5.57 \mathrm{kwh}$ of energy per day. The value is enough to supply occupants with needed energy without any backup supply from gasoline power generator. The raw material (biomass) is available so long as animal waste and/or 
the source plants exist. Therefore, bioenergy sources are not only cost effective but environment- friendly especially if well maintained.

\section{Conclusion}

Fossil fuel energy source has been proved not to be a secure option due to greenhouse gases emission which is the primary cause of global warming. Therefore, worldwide change is needed in order to avert the catastrophe of global warming. This is why the development of alternative energy sources is absolutely necessary. Four major alternative sources of energy - hydropower, solar, wind, biomass (including biogas and municipal solid waste) had been considered, and measured using the three indices for energy sustainability. Their availability, along with any likely shortcoming was also discussed. From the study, it was found that alternative energy sources have sufficient potential to develop a sustainable electricity system. The paper reveals that solar is the most favorable resource followed by biomass, Hydropower and wind in that order. The study further unraveled that, biomass energy source is readily available as every home provides and manages at least one septic tank which is capable of supplying that home with her energy needs. The exploration and exploitation of biomass as alternative energy should be encouraged by the government through her relevant agencies. This could be achieved by the formulation and enforcement of policies on the use of environmental friendly energy as alternative energy sources in the Nigerian Niger Delta. It is evidential that replacing fossil fuel-based energy sources with alternative energy sources will help the world achieve environmental sustainability. It therefore implied that, alternative energy sources exploitation would help in mitigating climate change, thereby providing an excellent means of meeting energy demand of future generations in Akwa Ibom State in particular, and the Niger Delta at large. With this in place, there will be reduction in greenhouse gases emissions, which in turn will contribute to the mitigation of climate change and provide a clean environment as well as clean energy for the present and future generations. Bioenergy guarantees lower emissions, low energy cost and reduction in environmental pollution.

\section{References}

[1] Owusu, P. A. \& Sarkodie, A. S. (2016). A review of renewable energy sources, sustainability issues and climate change mitigation. Available at https//doi.org/10.1080/23311916.2016.1167990.

[2] Asumadu-Sarkodie, S., \& Owusu, P. A. (2016). Multivariate co-integration analysis of the Kaya factors in Ghana. Environmental Science and Pollution Research. doi:10.1007/s11356-016-6245-9.

[3] Robert, E. M. (2018). Progress in developing realistic corrosion models. Structure and Infrastructure Engineering, 14 (7), 843-853.

[4] Tester, J. W. (2005). Sustainable Energy: Choosing among Options. London: MIT Press.
[5] Ajanovic, A. (2011). Biofuels versus food production: Does biofuels production increase food prices? Energy, 36, 20702076.

[6] Willey, J. D., Kieber, R. J., Eyman, M. S. B. \& Avery, G. B. (2000). Rainwater dissolved organic carbon: concentrations and global flux. Global Biogeoche Cycles, 14 (1), 139-148.

[7] Stechow, C. (2011). Renewable Energy Sources and Climate Change Mitigation. Cambridge, Cambridge University Press.

[8] Salem, A. A., Soliman, A. A. \& El-Haty, I. J. (2009). Determination of nitrogen dioxide, sulfur dioxide, ozone, and ammonia in ambient air using the passive sampling method associated with ion chromatographic and potentiometric analyses. Air Quality Atmosphere and Health, 2(3), 133-145.

[9] Evans, G. U. Evans, U. F. \& John, D. E. (2014). Causal modeling of marine pollutants as determinants of marine life extinction in the Nigerian coastal environment. Journal of Environmental and Water Resource, 3(8), 184-191.

[10] Pfeiffer, T. J., Summerfelt, S. T. \& Watten, B. (2011). Comparative performance of $\mathrm{CO}_{2}$ measuring methods: Marine aquaculture recirculation system application Aquacultural Engineering, 44 (1), 1-9.

[11] Kaygusuz, K. (2012). Energy for sustainable development: A case of developing countries. Renewable and Sustainable Energy Reviews, 16, 1116-1126.

[12] United States Energy Information Admiration (USEIA) (2018). Biomass Explained Basic. https://www.eia.gov/energyexplained/index.cfm?page=biomas s_home.

[13] Edenhofer, O., Pichs-Madruga, R., Sokona, Y., Seyboth, K., Matschoss, P., Kadner, S. \& Stechow, C. (2011). Renewable Energy Sources and Climate Changes Mitigation. Cambrige, Cambridge University Press.

[14] Tiwari, G. N., \& Mishra, R. K. (2011). Advanced renewable energy sources. Royal Society of Chemistry, London.

[15] Asumadu-Sarkodie, S., Owusu, P. A. \& Rufangura, P. (2015). Impact analysis of flood in Accra, Ghana. Advances in Applied Science Research, 6, 53-78.

[16] Abbasi, T. \& Abbasi, S. (2010). Renewable energy sources: Their impact on global warming and pollution. PHI Learning.

[17] Panwar, N., Kaushik, S. \& Kothari, S. (2011). Role of renewable energy sources in environmental protection: A review: Renewable and Sustainable Energy Reviews, 15, $1513-1524$

[18] Ahmad, S. \& Mattahar (2014). Selection of renewable energy sources for sustainable development of electricity generation system using analytic hierarchy process: A case of Malaysia. Renewable Energy, 63, 458-466.

[19] Lu, Y, Nakicenovic, N., Visbeck, M. \& Stevance, A. S. (2015). Policy: Five priorities for the UN sustainable development goals. Nature, 520, 432-433.

[20] Førsund, F. R. (2015). Hydropower Economics. New York, Springer.

[21] Martin, A. D. (2007). Understanding Anaerobic Digestion, Presentation to the Environmental Services Association, 16.10.07, esauk.org. 